University of Nebraska - Lincoln

DigitalCommons@University of Nebraska - Lincoln

1993

\title{
Effects of Predator Odors on Feeding in the Mountain Beaver (Aplodontia rufa)
}

\author{
Gisela Epple \\ J. Russell Mason \\ Dale L. Nolte \\ USDA-APHIS-Wildlife Services, Dale.L.Nolte@aphis.usda.gov \\ Dan L. Campbell
}

Follow this and additional works at: https://digitalcommons.unl.edu/icwdm_usdanwrc

Part of the Environmental Sciences Commons

\begin{abstract}
Epple, Gisela; Mason, J. Russell; Nolte, Dale L.; and Campbell, Dan L., "Effects of Predator Odors on Feeding in the Mountain Beaver (Aplodontia rufa)" (1993). USDA National Wildlife Research Center - Staff Publications. 821.

https://digitalcommons.unl.edu/icwdm_usdanwrc/821
\end{abstract}

This Article is brought to you for free and open access by the U.S. Department of Agriculture: Animal and Plant Health Inspection Service at DigitalCommons@University of Nebraska - Lincoln. It has been accepted for inclusion in USDA National Wildlife Research Center - Staff Publications by an authorized administrator of DigitalCommons@University of Nebraska - Lincoln. 


\title{
EFFECTS OF PREDATOR ODORS ON FEEDING IN THE MOUNTAIN BEAVER (APLODONTIA RUFA)
}

\author{
Gisela Epple, J. Russell Mason, Dale L. Nolte, and \\ DAN L. CAMPBell \\ Monell Chemical Senses Center, 3500 Market Street, \\ Philadelphia, PA 19104 (GE, DLN) \\ United States Department of Agriculture, Animal and Plant Health Inspection Service, \\ Denver Wildlife Research Center, \% Monell Chemical Senses Center, \\ 3500 Market Street, Philadelphia, PA 19104 (JRM) \\ United States Department of Agriculture, Animal and Plant Health Inspection Service, \\ Denver Wildlife Research Center, Olympia Field Station, \\ 3625 93rd Avenue, Southwest, Olympia, WA 98502 (DLC)
}

Consumption of food by Aplodontia rufa from bowls scented with control odors, secretion from anal glands of minks (Mustela vison), or urine from minks, bobcats (Felis rufus), and coyotes (Canis latrans) was studied. In two-choice control tests, subjects indiscriminately consumed apple from unscented bowls and from bowls scented with urine from an unfamiliar herbivore (Cavia porcellus), or with butyric acid. During two-choice tests offering apple from bowls scented with secretion from anal glands of minks and from bowls scented with butyric acid, significantly less apple was consumed from bowls containing mink scent. In two-choice tests in which apple was offered from bowls scented with urine from either mink, bobcat, coyote, or domestic dog, all predator urines reduced feeding. Habituation was studied by measuring consumption of dry pellets during continuous exposure to coyote urine for 5 days. Significantly less chow was consumed from bowls scented with coyote urine than from control bowls, indicating a lack of habituation to the predator scent. We conclude that predator scents act as natural repellents. The responsiveness to scents from several sympatric predators as well as from domestic dogs suggest an innate reaction to a signal, which is common to carnivores. The utility of predator scents in the control of browsing damage by mountain beavers should be explored.

Key words: Aplodontia rufa, mountain beaver, predator odors, feeding repellents.

Chemosensory detection may be an important aspect of the predator-avoidance strategy of many mammals, and behavioral responses to chemical cues from predators have been studied in some detail. MüllerSchwarze (1983) and Weldon (1990) have reviewed the older literature on responses to cues from mammalian predators. More recent studies have stressed the potential of predator scents as natural repellents. Such odors have been used in the laboratory and in the field to repel herbivores and to reduce feeding damage to a variety of plants. A number of studies have demonstrated the effects of feces, urine, and gland secretions, and of compounds isolated from these sources, on spacing, exploitation of food resources, and damage to plants in some Lagomorpha (Robinson, 1990; Sullivan, 1986; Sullivan and Crump, 1984, 1986a; Sullivan et al., 1985a), in several species of Microtus (Dickman and Doncaster, 1984; Gorman, 1984; Robinson, 1990; Stoddart, 1976, 1980, 1982; Sullivan et al., 1988a, 1990b), in the pocket gopher (Thomomys talpoides-Sullivan and Crump, 1986b; Sullivan et al., 1988b, 1990a), the woodchuck (Marmota monax-Swihart, 1991), and in 
the white rat (Rattus norvegicus-VernetMaury, 1980; Vernet-Maury et al., 1984). Extensive laboratory and field studies by Sullivan and coworkers, testing a number of synthetic components of predator scent, have resulted in the suggestion of a mixture of two constituents of secretion from anal glands of mustelids as a commercial rodent repellent (Merkens et al., 1991; Sullivan and Crump, 1986b; Sullivan et al., 1988a, 1988b, 1990a, 1990b).

Fecal material and urine from a variety of carnivores reduce feeding in ungulates, including roe deer (Capreolus capreolusVan Haaften, 1963), red deer (Cervus elaphus-Abbott et al., 1990), black-tailed deer (Odocoileus hemionus columbianus-Melchiors and Leslie, 1985; Müller-Schwarze, 1972, 1983; Sullivan et al., 1985b), whitetailed deer $(O$. virginianus-Swihart et al., 1991), domestic sheep, and cattle (Pfister et al., 1990). Effectiveness of predator odors as natural repellents is strongly influenced by characteristics of habitat, such as availability of cover (Merkens et al., 1991), and may depend on other factors, e.g., geographic distribution of predator and prey, duration of their geographic association, and cultural transmission of predator responses among prey (Swihart et al., 1991).

The present study examines the importance of chemical cues for predator avoidance in the mountain beaver (Aplodontia $r u f a$ ). This rodent is the only extant member of the primitive family Aplodontidae. Its distribution is limited to the Pacific Northwest of North America from southern British Columbia to central California. Mountain beavers inhabit underground tunnel systems that incorporate nest chambers, food caches, refuse chambers, and toilet areas (Martin, 1971). The species is strictly herbivorous, harvesting vegetation used for food as well as for nesting material. The diet includes ferns, grasses, and a number of species of shrubs and trees (Feldhamer and Rochelle, 1982). Because of the habit of girdling tree stems and cutting branches, Aplodontia does considerable damage to trees, particularly to commercially valuable conifer seedlings and saplings (Campbell and Evans, 1988).

Several of the avian and most of the mammalian predators sympatric with $A$. rufa appear to prey on this species, although the effects of predation on its population are poorly understood (Feldhamer and Rochelle, 1982). Where present, bobcats (Felis rufus) and coyotes (Canis latrans) seem to be the major mammalian predators taking mountain beavers above ground. In burrow systems, this role seems to be taken by minks (Mustela vison), and long-tailed weasels (Mustela frenata-Campbell, in press).

Mountain beavers forage predominantly above ground (Campbell, in press; Feldhamer and Rochelle, 1982), where they may be more vulnerable to predators than in burrow systems. Their small eyes (Nowak, 1991), and the poor behavioral response of captive individuals to stationary visual stimuli suggest that vision may not be the predominant sensory system involved in predator avoidance. A high sensitivity to chemical cues, which would alert mountain beavers to the presence of predators during foraging activities above ground, could be advantageous. We investigated the hypothesis that predator odors influence foraging by testing the effects of such scents on food consumption in the laboratory.

\section{METHODS}

A total of 13 adult mountain beavers (seven males, six females) served as subjects. Not all animals, however, were used in every experiment. The mountain beavers were trapped in Washington, and shipped to the Monell Chemical Senses Center, Philadelphia, Pennsylvania, where all experiments were performed. The animals had been in captivity for 6 weeks prior to the first experiment.

Mountain beavers primarily are nocturnal (Feldhamer and Rochelle, 1982). Therefore, the animals were maintained on a reversed light cycle, with infrared lamps providing dim light during the day. The number of hours of light and darkness mimicked seasonal changes in the $\mathrm{Pa}$ cific Northwest. 
Each animal was housed individually in a wiremesh cage consisting of two compartments (66 by 66 by $183 \mathrm{~cm}$ ) connected by a door at floor level. One of the compartments contained a 20-1 plastic bucket in which most animals constructed nests. Aspen chips covered the cage floor. Mountain beavers were provided free access to Purina Guinea Pig Chow and Mazur Omnivore A pellets. This diet was supplemented with fresh greens (dandelion, kale, crabapple branches), alfalfa, and apple. Water was available ad lib.

Urine from natural predators of $A$. rufa, i.e., bobcats, minks, and coyotes was purchased from M\&M Fur Company (Bridgewater, SD 57319). According to the supplier, urines were uncontaminated, except for the addition of an antifreezing compound to coyote urine. It is likely, however, that minor contaminants such as traces of feces and hair were present. To remove these, the urine was centrifuged at $4,000 \mathrm{rpm}$ for 20 $\mathrm{min}$. Aliquots of each pool were frozen at $-35^{\circ} \mathrm{C}$.

Freshly voided urine from the domestic dog, which is not a natural predator of mountain beavers, was collected from two male pets, centrifuged and stored in the same manner. Freshly voided urine from guinea pigs (Cavia procellus) and prairie voles (Microtus ochrogaster), used for control purposes, was collected from laboratory colonies, centrifuged, and stored as outlined above. All samples were thawed immediately prior to being used in a test.

Secretions from anal glands were collected by E. Zinkevitch from male farm-bred minks, following methods described by Sokolov et al. (1980). The pure secretion was stored in a refrigerator.

Experiments 1-4. - The effects of scent from predators and of control scents on the consumption of a highly preferred food, diced apple, were investigated using two-choice tests. Animals were presented with two stainless-steel bowls, each containing $20 \mathrm{~g}$ of diced apple ( $2-\mathrm{cm}$ cubes). Each bowl was $12 \mathrm{~cm}$ deep and had an 8-mm-wide rim. Stimulus scents, in the amounts specified below, were applied to the rim of each bowl, and small drops of the material were allowed to flow down on the inside of the container. Apple was added after the stimulus fluid had dried to avoid contamination of the food with the stimuli. The beavers had to bend over the scented rim of the bowl to retrieve the apple.

Animals were tested between 1000 and 1300 $h$. Each mountain beaver was tested once daily, and not $>3$ times/week. For each test, both bowls were introduced into the cage compartment that did not contain the nest, and were placed against the wall opposite the connecting door. They were spaced ca. $25 \mathrm{~cm}$ apart. After a 2-h test-period, the weight of apple left in each bowl was recorded. All subjects were tested twice with every set of stimuli in each experiment. The left-right position of the scented bowls was counterbalanced across the two replications on each subject and across subjects.

Experiment 1.-The effect of a novel control odor on feeding was investigated in 10 subjects. Each animal was tested twice with a choice between apple from an unscented bowl and from a bowl scented with $50 \mu \mathrm{l}$ of $2.5 \%$ butyric acid in mineral oil.

Experiment 2.-The effect of urine from an unfamiliar herbivore on food consumption was investigated in 12 subjects. Each animal was tested twice with a choice between apple offered in an unscented bowl and apple offered in a bowl scented with $500 \mu \mathrm{l}$ of pooled urine from male and female guinea pigs.

Experiment 3.-The effect of secretion from anal glands of minks and of a control odorant, butyric acid, on food consumption was investigated in 10 subjects. Each animal was tested twice with a choice between apple offered in a bowl scented with $50 \mu \mathrm{l}$ of pure secretion from anal glands and apple offered in a bowl scented with $50 \mu \mathrm{l}$ of $2.5 \%$ butyric acid in mineral oil.

Experiment 4. - The effect of urine from four predator species on food consumption was investigated in 12 subjects. Urine from three natural predators of Aplodontia, bobcats, coyote, and minks (Campbell, in press; Feldhamer and Rochelle, 1982), and from the domestic dog was used. Each animal was tested twice with a choice between apple in a bowl scented with $500 \mu \mathrm{l}$ of urine from each predator species and apple in a bowl scented with $500 \mu \mathrm{l}$ of urine from prairie voles. The animals were tested in a counterbalanced design. On each experimental day, four subjects were tested, one with bobcat urine, one with coyote urine, one with mink urine, and one with dog urine.

Experiment 5. - The effect of long-term exposure to predator odors on food consumption was investigated in five subjects. In the course of this habituation experiment, each animal was exposed to coyote urine continuously for 5 days while being housed in a large room ( 3.5 by 3.5 $\mathrm{m})$. The room was equipped with the nest bucket of the subject, two metal tunnels $(120 \mathrm{~cm}$ long, 
Predator scent Butyric acid

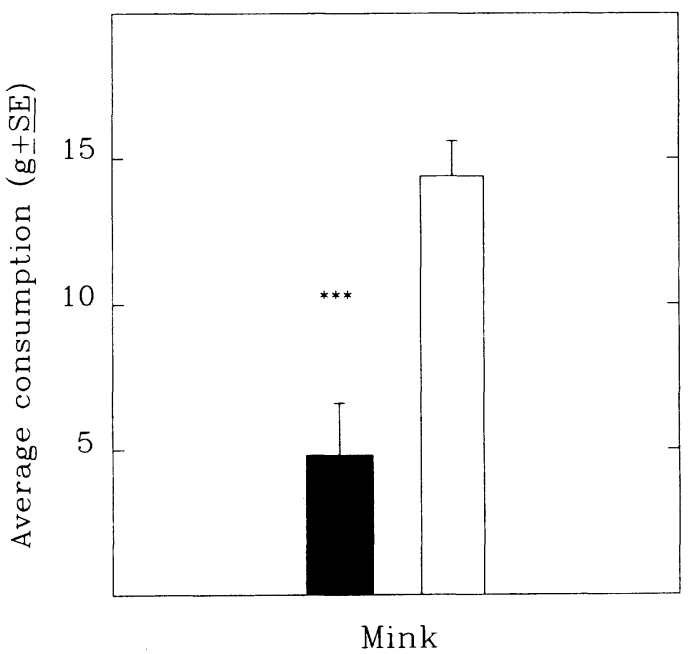

Fig. 1.-Average amount of apple consumed by mountain beavers from bowls scented with secretion from anal glands of minks and with butyric acid; ${ }^{* * *} P=0.001$, paired $t$-test.

$15 \mathrm{~cm}$ diameter) to increase environmental complexity, a water bowl, and two feeding stations located $3 \mathrm{~m}$ from each other. Each feeding station offered dry pellet diet in a bowl. One bowl was scented with coyote urine, while the other bowl was scented with water.

The feeding stations consisted of translucent plastic boxes $(40 \mathrm{~cm}$ long, $28 \mathrm{~cm}$ wide, $23 \mathrm{~cm}$ high) with 13 by $13-\mathrm{cm}$ entrances. These boxes were used to concentrate volatiles emanating from a scented ceramic food-bowl located inside each box. The bowls ( $23 \mathrm{~cm}$ in outside diameter) were fitted with loops of teflon tubing $(6.4 \mathrm{~mm}$ in inside diameter), which served as scent dispensers. The tubing featured 3-mm wide holes, spaced 5 $\mathrm{cm}$ apart. Strips of 2.5 -cm-wide gauze, inserted into each tube, served as wicks. The tubing loops, whose diameters were identical to those of the bowls, were clamped to each bowl, resting on its 2-cm-wide rim.

The scent dispensers were loaded by injecting $2 \mathrm{ml}$ of coyote urine or water through the holes of the tubing, distributing the fluids evenly throughout the loops. One of the two feeding stations, including bowl and loop, always was used to present coyote urine, while the other always was used to present water.

Each subject was introduced into the room 24 $\mathrm{h}$ before predator urine was presented. During this period, $70 \mathrm{~g}$ of dry pellets were available in both feeding stations. The food bowls were fitted with empty scent dispensers. Dry chow was the only food available throughout the adaptation and test periods.

A 5-day test-period followed adaptation. On each test day, at $1000 \mathrm{~h}$, the weight of chow remaining in the feeding stations was taken as a measurement of consumption. Fresh chow (70 g) was placed in each feeding station and the scent dispensers were loaded with $2 \mathrm{ml}$ of coyote urine or water. Scent dispensers were cleaned daily by discarding used gauze wicks and rinsing the tubing in running hot water, followed by $95 \%$ ethanol. New wicks were inserted into the dry tubes and the dispensers were loaded with urine or water. The location of boxes in the room remained constant throughout the 5 days of testing, but positions of urine-scented and water-scented stations were determined daily at random.

\section{RESUlTS}

When mountain beavers were presented with choices between apple from unscented bowls and from bowls scented with either butyric acid or guinea pig urine, they fed indiscriminately from both bowls, removing most of the apple (Experiment 1: scented with butyric acid $16.9 \pm 1.8 \mathrm{~g}$, unscented $16.5 \pm 1.3 \mathrm{~g}$; Experiment 2: scented with guinea pig urine $16.8 \pm 1.8 \mathrm{~g}$, unscented $17.7 \pm 1.8 \mathrm{~g})$. These results document that presence of unfamiliar, but behaviorally irrelevant odors does not inhibit feeding.

Significantly less apple was removed from the bowl scented with secretion from anal glands of mink than from the bowl scented with butyric acid (Experiment 3; Fig. 1). Likewise, in Experiment 4, significantly less apple was taken from bowls scented with urine from dogs, minks, bobcats, or coyotes than from bowls scented with urine from prairie voles (Fig. 2). There was no significant difference in the degree to which urine from the four predator species reduced food consumption. When predator odors were present, overall consumption was reduced. In control experiments the combined amount of apple removed from both bowls 


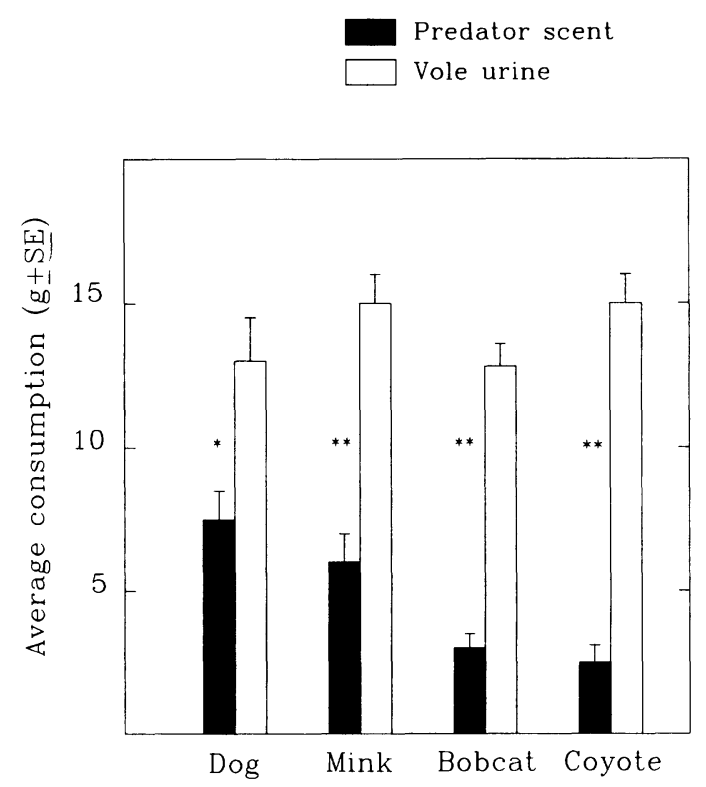

FIG. 2.-Average amount of apple consumed by mountain beavers from bowls scented with urine from dogs, minks, bobcats, or coyotes, and from bowls scented with vole urine; ${ }^{*} P=0.05$; ** $P=0.01$, analysis of variance with post-hoc Tukey tests.

was higher than in experiments where one of the bowls was scented with predator urine or secretion from anal glands (Fig. 3).

Throughout the 5 days of exposure to coyote urine in Experiment 5, mountain beavers consumed significantly less chow from the feeding station scented with predator urine than from the station scented with water (Fig. 4). Moreover, there was no significant difference in feeding over days of exposure, indicating that animals did not habituate to the predator odor.

\section{DisCussion}

Our studies show that mountain beavers respond to urine from several natural predators, as well as to secretions from the anal gland of minks by reducing food consumption when they encounter these stimuli around a food source. These materials appear to contain cues that function as natural repellents. Urine from the domestic dog has a similar effect. There was no statistically significant difference in the degree to which

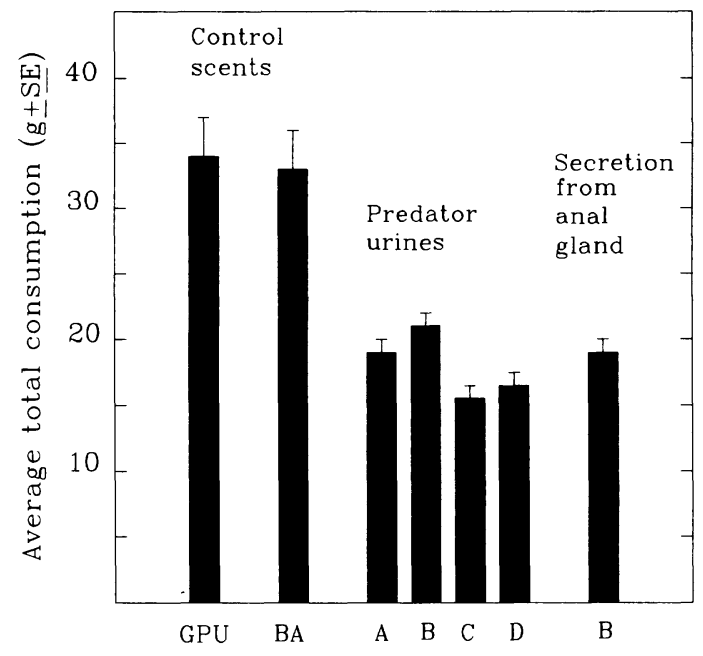

Fig. 3.-Average amount of apple consumed by mountain beavers from both bowls in twochoice tests in which no predator odor was present and in two-choice tests during which one bowl was the source of a predator odor: GPU, guinea pig urine; BA, butyric acid; A, dog; B, mink; C, bobcat; $\mathrm{D}$, coyote.

urine from the four predator species reduced feeding. However, Fig. 2 shows that among the urine samples, coyote urine tended to be the most effective and dog urine the least effective stimulus.

Feeding responses of mountain beavers during continuous exposure to coyote urine show that animals did not habituate to the predator scent over a 5-day period. While it is possible that habituation eventually occurs if the animals are exposed to predator scents over a long period of time, studies by Nolte et al. (in press) suggest that these odors inhibit feeding for at least 2 weeks when alternative food sources are present. Mountain beavers, presented with foliartreated Douglas fir (Pseudotsuga menziesii) seedlings, avoided those seedlings treated with coyote urine for the duration of a 2-week experiment (Nolte et al., in press).

Failure to habituate to predator odors also has been found in other studies. Bobcat urine, which inhibits gnawing of fruit trees associated with scent-marking by woodchucks, retains its effectiveness for $>3$ months (Swihart, 1991). Feeding suppres- 
Coyote Urine Water

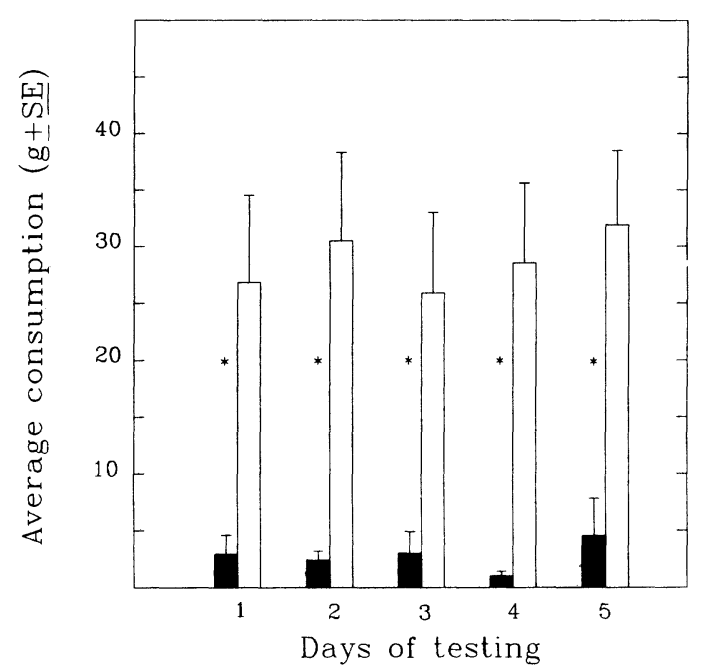

FIG. 4.-Average amount of dry chow consumed by mountain beavers throughout 5 days from feeding stations scented with coyote urine and from feeding stations scented with water; * $P=0.02$, analysis of variance with post-hoc Tukey-tests.

sion in snowshoe hares (Lepus americanus) and area avoidance in Microtus in response to components from anal glands of mustelids persist for months (Sullivan and Crump, 1984; Sullivan et al., 1988a). Moreover, longevity of constituents of predator odors or their synthetic formulations can be increased by slow-release devices (Sullivan et al., 1988a, 1988b, 1990a, 1990b).

The effectiveness of urine from the domestic $\operatorname{dog}$ as a feeding deterrent in the mountain beaver is somewhat surprising. Sullivan et al. (1985a) found dog urine to be ineffective in reducing browsing damage to conifer seedlings by snowshoe hares. There is some variability in the extent to which different mammalian species respond to chemosensory cues from sympatric and allopatric predator species and from carnivores that do not regularly prey on them. Microtus agrestis avoids traps scented with the secretion from the anal gland of the weasel (Mustela nivalis), but also traps scented with urine of the jaguar (Panthera onca) or tiger (Panthera tigris-Stoddart, 1976, 1980, 1982). Microtus arvalis avoids secretion from anal glands of the stoat (Mustela erminea), a predator from which voles on Orkney Island had been separated for a considerable part of their history (Gorman, 1984). Dickman and Doncaster (1984) report that small rodents avoid scent from the badger (Taxidea taxus), a species absent from their study area.

Roe deer, red deer, and black-tailed deer show feeding inhibition in response to fecalchemical cues derived from the African lion (Panthera leo), snow leopard (Panthera unca), and tiger (Abbott et al., 1990; MüllerSchwarze, 1972; Van Haaften, 1963). Indeed, Abbott et al. (1990) recently have prepared an organic-solvent extract from lion feces, and synthetic formulations of compounds found in lion feces, which are as effective as the total fecal material in reducing feeding by red deer.

Although mammals respond to scents from allopatric predators, chemical cues from sympatric species often are more effective. Black-tailed deer show strong avoidance of food scented with fecal material from cougars (Felis concolor) and coyotes, while fecal odors from lions, leopards, and tigers are less effective (MüllerSchwarze, 1972). Melchiors and Leslie (1985) found fecal odors from bobcats more effective in reducing browsing by blacktailed deer than fecal odors from cougars, coyotes, or wolves. Bobcat and coyote urine reduce browsing by white-tailed deer, with bobcat urine being more effective than coyote urine, whereas human urine has little effect (Swihart et al., 1991). In contrast, Sullivan et al. (1985b) found that black-tailed deer are more repelled by coyote than by bobcat urine.

The responses to chemical cues from allopatric predators and the failure to habituate to predator odors have been interpreted as evidence that responses to these stimuli are innate (Dickman and Doncaster, 1984; Müller-Schwarze, 1972; Robinson, 1990; 
Stoddart, 1980). This notion is supported by the responses of hand-raised, predatornaive deer to carnivore feces (Abbott et al., 1990; Müller-Schwarze, 1972) and by the responses of Microtus species, living on the predator-free island of Orkney, to chemical cues from stoat (Gorman, 1984).

In those cases in which predator and prey have been sympatric at some time in their evolutionary history, aversion to cues from such predators may well be the result of atavistic-adaptive responses (Abbott et al., 1990; Robinson, 1990). Conversely, it is conceivable that responses to chemical cues derived from non-native predators do not involve recognition of the predator as a species. They may be due to a common carnivore signal, e.g., sulfur-containing odorants produced during the digestion of meat and fat (Abbott et al., 1990; Mason et al., in press). The effect of dog urine on feeding in the mountain beaver may represent a response to a common carnivore signal. If such signals exist, a drastic change in diet should alter the stimulus qualities of carnivore urine. A largely vegetarian diet should reduce its repellency. This hypothesis is testable.

\section{ACKNOWLEDGMENTS}

The studies were supported through Cooperative Agreement Number 12-34-41-CC40 [CA] between the Denver Wildlife Research Center and the Monell Chemical Senses Center. The assistance of Olympia Field Station personnel in trapping and shipping animals is gratefully acknowledged, as are the editorial comments of $R$. Swihart and an anonymous referee.

\section{Literature Cited}

Abbott, D. H., D. A. Baines, C. G. Faulkes, D. C. Jennens, P. C. Y. K. Ning, AND A. J. Tomlinson. 1990. A natural deer repellent: chemistry and behavior. Pp. 599-609, in Chemical signals in vertebrates 5 (D. W. Macdonald, D. Müller-Schwarze, and S. E. Natynczuk, eds.). Oxford University Press, Oxford, United Kingdom, 659 pp.

CAmpbell, D. L. In press. Mountain beaver. In Prevention and control of wildlife damage (S. E. Hyngstrom and R. M. Timm, eds.). University of Nebraska Cooperative Extension Service, in Cooperation with United States Department of Agriculture, Animal and Plant Health Inspection Service, Animal Dam- age Control, and Great Plains Agricultural Council, Lincoln, Nebraska.

Campbell, D. L., and J. Evans. 1988. Recent approaches to controlling mountain beavers (Aplodontia rufa) in Pacific Northwest forests. Proceedings of the Vertebrate Pest Conference, 13:183-187.

Dickman, C. R., AND C. P. Doncaster. 1984. Responses of small mammals to red fox (Vulpes vulpes) odour. Journal of Zoology (London), 204:419-423.

Feldhamer, G. A., AND J. A. Rochelle. 1982. Mountain beaver-Aplodontia rufa. Pp. 167-175, in Wild mammals of North America (J. A. Chapman and G. A. Feldhamer, eds.). The Johns Hopkins University Press, Baltimore, Maryland, $1147 \mathrm{pp}$.

Gorman, M. L. 1984. The responses of prey to stoat (Mustela erminea) scent. Journal of Zoology (London), 202:419-423.

MARTIN, P. 1971. Movements and activities of the mountain beaver (Aplodontia rufa). Journal of Mammalogy, 52:717-723.

Mason, J. R., G. Epple, AND D. L. Nolte. In press. Semiochemicals and improvements in rodent control. In Ontogeny and social transmission of food preferences in mammals: basic and applied research (B. E. Galef, P. Valsecchi, and M. Mainardi, eds.). Harwood Academic Press, London, United Kingdom.

Melchiors, M. A., ANd C. A. Leslie. 1985. Effectiveness of predator fecal odors as black-tailed deer repellents. The Journal of Wildlife Management, 49: 358-362.

Merkens, M., A. S. Harestad, and T. Sullivan. 1991. Cover and efficacy of predator-based repellents for Townsend's vole, Microtus townsendii. Journal of Chemical Ecology, 17:401-412.

MÜLlER-SCHWARZE, D. 1972. Responses of young black-tailed deer to predator odors. Journal of Mammalogy, 53:393-394.

- 1983. Experimental modulation of behavior of free-ranging mammals by semiochemicals. Pp. 235-244, in Chemical signals in vertebrates 3 (D. Müller-Schwarze and R. H. Silverstein, eds.). Plenum Press, New York, 368 pp.

Nolte, D. L., J. P. Farley, D. L. Campbell, J. R. MASON, AND G. EPPle. In press. Potential repellents to prevent mountain beaver damage. Crop Production.

NowAK, R. M. 1991. Walker's mammals of the world. Fifth ed. The Johns Hopkins University Press, Baltimore, Maryland, 1:1-642.

Pfister, J. A., D. Müller-Schwarze, AND D. F. BAlPH. 1990. Effects of predator fecal odors on feed selection by sheep and cattle. Journal of Chemical Ecology, 16:573-583.

RobINSON, I. 1990. The effect of mink odour on rabbits and small mammals. Pp. 567-572, in Chemical signals in vertebrates 5 (D. W. Macdonald, D. Müller-Schwarze, and S. E. Natynczuk, eds.). Oxford University Press, Oxford, United Kingdom, 659 pp.

Sokolov, V. E., ET AL. 1980. Secretion and secretory tissues of the anal sac of the mink, Mustela vison. Journal of Chemical Ecology, 6:805-825.

StodDART, D. M. 1976. Effect of the odour of weasels (Mustela nivalis L.) on trapped samples of their prey. Oecologia (Berlin), 22:439-441. 
1980. Some responses of a free living community of rodents to the odors of predators. Pp. 110 , in Chemical signals. Vertebrates and aquatic invertebrates (D. Müller-Schwarze and R. M. Silverstein, eds.). Plenum Press, New York, 445 pp.

. 1982. Demonstrations of olfactory discrimination by the short-tailed vole, Microtus agrestis L. Animal Behaviour, 30:293-294.

Sullivan, T. P. 1986. Influence of wolverine (Gulo gulo) odor on feeding behavior of snowshoe hares (Lepus americanus). Journal of Mammalogy, 67:385388.

Sullivan, T. P., AND D. R. CRUMP. 1984. Influence of mustelid scent gland compounds on the suppression of feeding by snowshoe hares (Lepus americanus). Journal of Chemical Ecology, 10:1809-1821.

. 1986a. Feeding responses of snowshoe hares (Lepus americanus) to volatile constituents of red fox (Vulpes vulpes) urine. Journal of Chemical Ecology, 12:229-239.

. 1986b. Avoidance response of pocket gophers (Thomomys talpoides) to mustelid anal gland compounds. Pp. 519-531, in Chemical signals in vertebrates 4, ecology, evolution and comparative biology (D. Duvall, D. Müller-Schwarze, and R. M. Silverstein, eds.). Plenum Press, New York, 742 pp.

Sullivan, T. P., D. R. CRump, AND D. S. Sullivan. $1988 a$. Use of predator odors as repellents to reduce feeding damage by herbivores. III. Montane and meadow voles (Microtus montanus and Microtus pennsylvanicus). Journal of Chemical Ecology, 14: 363-377.

- $1988 b$. Use of predator odors as repellents to reduce feeding damage by herbivores. IV. Northern pocket gophers (Thomomys talpoides). Journal of Chemical Ecology, 14:379-389.

Sullivan, T. P., L. O. Nordstrom, AND D. S. SulliVAN. 1985a. Use of predator odors as repellents to reduce feeding damage by herbivores. I. Snowshoe hares (Lepus americanus). Journal of Chemical Ecology, 11:903-909.

․ $1985 b$. Use of predator odors as repellents to reduce feeding damage by herbivores. II. Blacktailed deer (Odocoileus hemionus columbianus). Journal of Chemical Ecology, 11:921-935.

Sullivan, T. P., D. R. Crump, H. Wieser, AND A. DixON. 1990a. Responses of pocket gophers (Thomomys talpoides) to an operational application of synthetic semiochemicals of stoat (Mustela erminea). Journal of Chemical Ecology, 16:941-949.

1990b. Comparison of release devices for stoat (Mustela erminea) semiochemicals used as montane vole (Microtus montanus) repellents. Journal of Chemical Ecology, 16:951-957.

SwIHART, R. K. 1991. Modifying scent marking behavior to reduce woodchuck damage to fruit trees. Ecological Applications, 1:98-103.

Swihart, R. K., J. J. Pignatello, and M. J. I. Mattina. 1991. Aversive responses of white-tailed deer, Odocoileus virginianus, to predator urines. Journal of Chemical Ecology, 17:767-777.

Van HaAften, J. L. 1963. A natural repellent. Pp. 389-392, in Transactions of the Congress of the International Union of Game Biologists. The Nature Conservancy, London, United Kingdom, 6:1-625.

Vernet-MaURY, E. 1980. Trimethyl-thiazoline in fox feces: a natural alarming substance for the rat. $\mathrm{Pp}$. 407, in Olfaction and taste VII (H. van der Starre, ed.). Information Retrieval Ltd. Press, Washington, D.C., $500 \mathrm{pp}$.

Vernet-Maury, E., E. H. Polak, and A. Demael. 1984. Structure/activity relationship of stress inducing odorants in the rat. Journal of Chemical Ecology, 10:1007-1018.

WELDON, P. J. 1990. Responses by vertebrates to chemicals from predators. Pp. 500-521, in Chemical signals in vertebrates 5 (D. W. Macdonald, D. Müller-Schwarze, and S. E. Natynczuk, eds.). Oxford University Press, Oxford, United Kingdom, 659 pp.

Submitted 26 May 1992. Accepted 22 September 1992. Associate Editor was Stephen H. Vessey. 